\title{
Sectoral Mobility and Unemployment with Heterogeneous Moving Costs*
}

\author{
Damba Lkhagvasuren ${ }^{\dagger}$ \\ Concordia University and CIREQ
}

\author{
Roy Nitulescu ${ }^{\ddagger}$ \\ Concordia University
}

May 14, 2013

\begin{abstract}
A simple equilibrium model of sectoral reallocation is developed in order to study the impact of heterogeneous moving costs on unemployment. The model blends key elements of standard sectoral reallocation theory and the competitive search model. Heterogeneity in moving costs is introduced via mobile and immobile workers. According to the model, the share of mobile workers lowers aggregate unemployment. The model reveals that when labor mobility is driven by an idiosyncratic sector-worker match effect, the share of mobile workers raises the unemployment rate of immobile workers. However, when labor mobility is driven by a sectoral level aggregate disturbance, mobile workers can have a non-monotonic, but globally negative impact on the unemployment rate of immobile workers.
\end{abstract}

Keywords: sectoral unemployment, aggregate unemployment, island model, competitive search, net and gross mobility, homeownership, aging population

JEL Classifications: J61, J62, J63, J64

\footnotetext{
${ }^{*}$ We would like to thank an anonymous referee, Mark Bils, Effrosyni Diamantoudi, Gordon Fisher and David Fuller for helpful comments and suggestions.

${ }^{\dagger}$ Department of Economics, Concordia University, 1455 de Maisonneuve Blvd. West, Montreal, Quebec, H3G 1M8 Canada; Email: damba.1khagvasuren@concordia.ca.

${ }^{\ddagger}$ Department of Economics, Concordia University, 1455 de Maisonneuve Blvd. West, Montreal, Quebec, H3G 1M8 Canada; Email: roy.nitulescu@gmail.com.
} 


\section{Introduction}

We consider a simple equilibrium model of unemployment and sectoral reallocation to explore how the composition of mobile versus immobile workers affects unemployment. The issue is important because sectoral mobility differs considerably across individuals and the relative share of more mobile versus less mobile workers shifts over time. For example, according to Moscarini and Thomsson (2007), an individual's age is negatively correlated with his occupational and industrial mobility. Thus, it seems natural to ask whether the aging of the labor force has an impact on the labor market outcomes of both young and old workers. One can also ask a similar question in the context of geographical mobility, as migration is much lower among older workers (e.g., Topel (1986) and Greenwood (1997)). Another issue, which is more related to the recent experiences of the U.S., concerns the collapse of the housing market. Specifically, there is a valid concern as to whether an increase in the number of homeowners trapped in their homes by negative home equity has had an adverse impact on the aggregate labor market. ${ }^{1}$

We start with the two-sector equilibrium model of Rogerson (1987), which in turn builds on Lucas and Prescott (1974). His model has the following features that are important for the purpose of the current paper. First, the marginal productivity of labor is decreasing at the sectoral level and shifts with sector-specific shocks. Second, a worker can move across sectors for a better job opportunity. We augment these features with the following three elements. First, within each sector, firms and workers meet through competitive search (e.g., Moen, 1997 and Rogerson, Shimer and Wright, 2005). ${ }^{2}$ Second, in addition to the sector-specific shock common to workers within the same sector, there is also an idiosyncratic shock specific to the sector-worker match as in Jovanovic and Moffitt (1990). Third, the cost of moving between the two sectors differs across workers. In particular, some workers can move across sectors costlessly, while the others are immobile.

Because of the idiosyncratic productivity shock, a worker may move from one sector to another, even if labor market conditions are the same between the two sectors. Consequently, in the model, a sector can experience a simultaneous inflow and outflow of workers. Below, for brevity, these simultaneous in- and outflows driven by the idiosyncratic productivity shock will be referred to as gross mobility, while labor mobility driven by a sector-specific

\footnotetext{
${ }^{1}$ For studies examining the relationship between homeownership and unemployment, see, for example, Oswald (1997, 1999); Munch, Rosholm and Svarer (2006); Coulson and Fisher (2009); Head and Lloyd-Ellis (2012) and Valletta (2012).

${ }^{2}$ The interaction of within-sector trading frictions and sectoral mobility is also considered in other studies. For example, Lkhagvasuren $(2007,2012)$ uses a similar multi-sector setting to analyze local labor market dynamics in the U.S. Carrillo-Tudela and Visschers (2013) develop an equilibrium multi-sector model with within-sector trading frictions to study the cyclicality of sectoral reallocation.
} 
shock will be referred to as net mobility.

The model shows that net mobility driven by a sector-specific shock lowers productivity differences between sectors while reducing unemployment differences across sectors. More important, in the presence of such net mobility, the share of mobile workers can have a nonmonotonic, but globally negative impact on the unemployment rate of immobile workers. The results also show that the combination of gross mobility and firm-worker trading frictions introduces a novel equilibrium effect from having mobile workers. Specifically, when labor mobility is driven by a sector-worker match effect, the share of mobile workers raises overall productivity of workers within each sector. While such an overall increase in productivity raises employment within each sector, it raises the unemployment rate among immobile workers due to the decreasing returns to scale at the sectoral level. So, the equilibrium effect of heterogeneous moving costs differs depending on how mobility is modeled. The model also shows that, regardless of whether sectoral mobility is modeled as net or gross mobility, aggregate unemployment and the share of mobile workers are negatively related. ${ }^{3}$

These results suggest that ignoring gross mobility or match-specific effects can lead to an erroneous conclusion that the share of mobile workers lowers the unemployment of the rest of the workers, while its true effect can be the opposite. Moreover, judging a multi-sector model by its predictions on aggregate variables might introduce an important oversight regarding the underlying economic mechanisms. Therefore, the micro-level relationship between mobility and productivity are important for understanding the impact of mobility on unemployment.

The outline of the rest of the paper is as follows. Section 2 constructs a simple equilibrium model of sectoral mobility and unemployment while allowing for both net and gross mobility. Section 3 considers a special case of the model in which there is only net mobility. Section 4 considers a version of the model in which each sector can experience a simultaneous inflow and outflow without net mobility. Section 5 summarizes the conclusions.

\section{Model}

\section{$2.1 \quad$ Environment}

The economy consists of two sectors indexed by $j \in\{0,1\}$. Each of these sectors is initially populated by a unit measure of workers. There is also a continuum of firms in each sector. A worker can be employed or unemployed. Being employed means being matched with a

\footnotetext{
${ }^{3}$ This is consistent with the procyclicality of mobility studied by Moscarini and Thomsson (2007), Kambourov and Manovskii (2009), Lkhagvasuren (2012) and Carrillo-Tudela and Visschers (2013).
} 
firm. Firms look for workers by creating vacancies. Unemployed workers and vacancies meet according to a matching technology. Each sector is subject to a shock that affects the output of all firms operating in that sector. Let $z_{0}$ and $z_{1}$ denote these shocks to sectors 0 and 1, respectively. Moreover, workers in the same sector can differ by their idiosyncratic productivity shock $x$.

The economy lasts only one period, but it unfolds in four stages. At the beginning of the economy, all workers are unemployed. In the second stage, workers observe their idiosyncratic productivity shock, $x$, and the sector-specific shocks, $z_{0}$ and $z_{1}$. Given these shocks, workers decide whether they should stay in their current sector and look for a job or move to the other sector to search for a better opportunity. In the third stage, as a result of job search and vacancy creation, matches are formed. In the fourth and final stage, the matched firms and workers produce, while unmatched workers remain unemployed.

The cost of creating a vacancy is $k$. The cost of moving between two sectors can differ across workers. For tractability purposes, we impose the condition that some workers have a prohibitive moving cost, while the rest of the workers can move costlessly between sectors. Workers who have prohibitive moving costs are referred to as immobile workers, while those who have zero moving costs are referred to as mobile workers. Let $\mu$ denote the share of mobile workers.

\subsection{Production}

Consider a matched firm whose employee's productivity is $x$. Depending on whether the firm operates in sector 0 or sector 1 , its output is given by

$$
y_{0}(x)=z_{0}(1-x) E_{0}^{-\phi}
$$

or

$$
y_{1}(x)=z_{1}(1+x) E_{1}^{-\phi},
$$

where $0<\phi<1$, and $E_{0}$ and $E_{1}$ are employment in sector 0 and 1 , respectively. This production function reflects key elements of the model. First, as in standard sectoral reallocation theory (e.g., Lucas and Prescott (1974) and Rogerson (1987)), the marginal productivity of labor is decreasing at the sectoral level. ${ }^{4}$

Second, as in Moscarini and Vella (2008), the idiosyncratic productivity shock $x$ is purely sector-specific in the sense that a worker who is more productive in a particular sector is less productive in the other sector. The idiosyncratic productivity shock $x$ is drawn from a

\footnotetext{
${ }^{4}$ Also, see Coen-Pirani (2010) and Rogerson, Visschers and Wright (2009).
} 
symmetric distribution $G$ on the interval $[-\sigma, \sigma]$. For example, consider a worker in sector 1 who has just observed his idiosyncratic productivity shock, $x$. If $x$ is much lower than zero, moving to sector 0 may greatly improve his productivity. Conversely, if the idiosyncratic shock of a worker in sector 0 is much higher than zero, that worker may become more productive by moving to sector 1 .

\subsection{Matching technology}

Let $\tilde{u}_{j}(x)$ denote the number of workers searching for a job at productivity level $x$ in sector $j$. Similarly, let $v_{j}(x)$ denote the number of firms looking for a worker at the same productivity level in the same sector. Consistent with Petrongolo and Pissarides (2001), the number of matches formed between these workers and firms is given by

$$
N\left(v_{j}(x), \tilde{u}_{j}(x)\right)=A\left(v_{j}(x)\right)^{\theta}\left(\tilde{u}_{j}(x)\right)^{1-\theta},
$$

where $A>0$ represents the efficiency of the matching technology, and $\theta>0$ represents its elasticity. An unemployed worker searching for a job in sector $j$ at productivity level $x$ finds a job with probability $f\left(q_{j}(x)\right)=A\left(q_{j}(x)\right)^{-\theta}$, where $q_{j}(x)=\tilde{u}_{j}(x) / v_{j}(x)$ is the queue length. Similarly, one of the $v_{j}(x)$ vacancies is filled with probability $\alpha\left(q_{j}(x)\right)=A\left(q_{j}(x)\right)^{1-\theta}$.

\subsection{Value functions}

A worker who did not find a job receives income $b$, which may consist of the imputed value of leisure as well as unemployment insurance payments. Unemployment income $b$ is lower than a firm's output: $b<y_{j}(x)$ for all $j$ and $x .{ }^{5}$ For employed workers, wages are determined through competitive search as postulated in Moen (1997). In particular, as in Rogerson et al. (2005), firms post wages to maximize their expected profit and workers direct their search to the most attractive firms within the sector. Let $w_{j}(x)$ denote the wage posted at productivity level $x$ in sector $j$.

Let $S_{j}(x)$ denote the utility value of searching for a job in sector $j$ to a worker with idiosyncratic productivity shock $x$, and let $M_{1-j}(x)$ denote the utility value of moving to sector $1-j$ for the same worker. Then,

$$
S_{j}(x)=b+f\left(q_{j}(x)\right)\left(w_{j}(x)-b\right)
$$

\footnotetext{
${ }^{5}$ In our analysis, we consider ex-ante identical workers and assume that unemployment income $b$ is the same among workers with different productivity shocks. One can allow $b$ to increase with the idiosyncratic productivity shock $x$ to reflect the possibility that more productive workers value leisure more. However, using the results below in Proposition 2, one can see that such a variation in income $b$ is inconsequential for the results, as long as the job-finding rate increases with productivity (see equation (35)).
} 
and

$$
M_{1-j}(x)=b-c+f\left(q_{1-j}(x)\right)\left(w_{1-j}(x)-b\right),
$$

where $c$ denotes moving cost. As stated earlier, $c$ is zero for mobile workers and infinitely large for immobile workers.

From the perspective of a firm, the utility value of creating a job vacancy at the productivity level $x$ in sector $j$ is denoted $V_{j}(x)$. Then,

$$
V_{j}(x)=\max _{w_{j}(x)}\left\{-k+\alpha\left(q_{j}(x)\right)\left(y_{j}(x)-w_{j}(x)\right)\right\}
$$

Firms post vacancies to satisfy equation (5), while workers direct their search to the most attractive offers. In other words, equation (3) is taken as a constraint for solving equation (5). All rents from vacancy creation are exhausted: for each pair $(j, x)$,

$$
V_{j}(x)=0
$$

\subsection{Equilibrium}

Solving for a labor market equilibrium of a sector amounts to finding the wage and queue length at each productivity level $x$ in that sector.

\subsubsection{Wages}

Combining equations (5) and (6) yields:

$$
\frac{k}{\alpha\left(q_{j}(x)\right)}=y_{j}(x)-w_{j}(x) .
$$

Next, a firm's problem can be written as

$$
\max _{w_{j}(x)}\left\{\alpha\left(q_{j}(x)\right)\left(y_{j}(x)-w_{j}(x)\right)\right\}
$$

subject to equation (3). Then, as in Rogerson et al. (2005), one can obtain

$$
\alpha^{\prime}\left(q_{j}(x)\right)\left(y_{j}(x)-b\right)=f\left(q_{j}(x)\right)\left(w_{j}(x)-b\right) .
$$

Combining this with equations (1) and (2), wages can be rewritten as

$$
w_{0}(x)=\theta b+(1-\theta)(1-x) z_{0} E_{0}^{-\phi}
$$


and

$$
w_{1}(x)=\theta b+(1-\theta)(1+x) z_{1} E_{1}^{-\phi} .
$$

Remark 1 (Uniqueness). Within each sector, the wage $w_{j}(x)$ is unique for the idiosyncratic productivity shock, $x$.

Remark 2 (Wage profile). Within each sector, the wage $w_{j}(x)$ grows with productivity $y_{j}(x)$.

\subsubsection{Queue length}

Using the free-entry condition in equation (7) and the wages in equations (10) and (11), it can be shown that

$$
\frac{1}{\left(q_{0}(x)\right)^{1-\theta}}=\frac{A \theta}{k}\left((1-x) z_{0} E_{0}^{-\phi}-b\right)
$$

and

$$
\frac{1}{\left(q_{1}(x)\right)^{1-\theta}}=\frac{A \theta}{k}\left((1+x) z_{1} E_{1}^{-\phi}-b\right)
$$

where $0<\theta<1$ and $q_{j}(x)>0$ for all $j$ and $x$. Equations (12) and (13) imply that the queue length $q_{j}(x)$ is unique for $x$ and decreases with productivity $y_{j}(x)$ for each $j$ (see Figure 3 ). Using these results, the following claim can be made:

Remark 3 (Job-finding rate and productivity). The job-finding rate $f\left(q_{j}(x)\right)$ increases with productivity $y_{j}(x)$ for each $j$.

So, both the wage and the job-finding rate increase with productivity. Specifically, in sector 1 (in sector 0 ), individuals with higher (lower) $x$ have a larger wage and a higher job-finding rate.

\subsubsection{Mobility and the labor force}

Given a nonzero dispersion of the idiosyncratic productivity (i.e., when $\sigma>0$ ), for mobile workers, there should exist an indifference productivity level $x_{j}^{*} \in(-\sigma, \sigma)$ such that, for $j \in\{0,1\}$,

$$
S_{j}\left(x_{j}^{*}\right)=M_{1-j}\left(x_{j}^{*}\right) .
$$

Then, a mobile worker of sector 1 will move to sector 0 if the person's idiosyncratic shock is below $x_{1}^{*}$. Similarly, a mobile worker of sector 0 will move to sector 1 if the shock of that worker is above $x_{0}^{*}$.

Let $\Psi_{j}$ denote the decision rule governing whether a mobile worker in sector $j$ stays in the current sector: $\Psi_{1}(x)$ takes on the value 1 if $x \geq x_{1}^{*}$ and 0 otherwise, while $\Psi_{0}(x)$ takes 
on the value 1 if $x \leq x_{0}^{*}$ and 0 otherwise. Then, once workers are reallocated, the labor force of sector $j \in\{0,1\}$ becomes

$$
L_{j}=1+\frac{\mu}{2 \sigma} \int_{-\sigma}^{\sigma}\left(\Psi_{j}(x)-\Psi_{1-j}(x)\right) d x .
$$

\subsubsection{Employment}

Notice that wages, queue lengths and mobility decisions are obtained for a given level of employment. Therefore, in order to characterize the equilibrium, it is necessary to determine how employment in each sector is related to mobility and queue length. Using the decision rule $\Psi$, employment in sector $j \in\{0,1\}$ is

$$
E_{j}=\frac{1}{2 \sigma} \int_{-\sigma}^{\sigma} f\left(q_{j}(x)\right) d x+\frac{\mu}{2 \sigma} \int_{-\sigma}^{\sigma}\left(\Psi_{j}(x)-\Psi_{1-j}(x)\right) f\left(q_{j}(x)\right) d x .
$$

The economy-wide unemployment rate is

$$
u=1-\frac{E_{1}+E_{2}}{2}
$$

Let $\tilde{m}_{j}(x)$ denote the measure of mobile workers looking for a job in sector $j$ at productivity level $x: \tilde{m}_{j}(x)=\left(1+\Psi_{j}(x)-\Psi_{1-j}(x)\right) \mu /(2 \sigma)$. The unemployment rates of mobile and immobile workers are, respectively,

$$
u_{0}=1-\frac{1}{2 \mu} \int_{-\sigma}^{\sigma}\left(\tilde{m}_{0}(x) f_{0}(x)+\tilde{m}_{1}(x) f_{1}(x)\right) d x
$$

and

$$
u_{\infty}=1-\frac{1}{2} \int_{-\sigma}^{\sigma}\left(f_{0}(x)+f_{1}(x)\right) d G(x) .
$$

Using these results, it can be seen that the share of mobile versus immobile workers plays an important role in labor market equilibrium. More important, in light of equations (12), (13) and (16), labor mobility affects the job-finding rate of both mobile and immobile workers. For the remainder of the paper, we analyze the impact of $\mu$ on the labor market outcomes of mobile and immobile workers. In doing so, we consider two distinct versions of the model in the next two sections. In Section 3, we consider the special case of the model in which labor mobility is in one direction only. This special case is referred to as the net mobility model. Then, in Section 4, we consider a version of the model in which a sector can experience simultaneous and equal in- and out-migration, without any change in the sectoral labor force. With a slight abuse of language, this version of the model is referred to as the gross 
mobility model. These two versions of the model are complementary in the sense that labor flows occurring at the sectoral level can be decomposed into net mobility and flows that fully cancel out at the sectoral level.

\section{$3 \quad$ Net mobility effects}

Here agents in the same sector do not differ by their productivity. In particular, we consider the case in which $\sigma=0$ and thus, for each $j$, a firm's output is simplified to $y_{j}(x)=z_{j} E_{j}^{-\phi}$. Clearly, when $z_{0}=z_{1}$, no worker will move. However, if sector-specific shocks (hereinafter sector shock) differ, some mobile workers from the sector with the worse shock will move to the one with the better shock in order to obtain a gain in productivity while generating net mobility. In this section, we now assume that $z_{0}<z_{1}$. Let $m$ denote the number of people moving from sector 0 to sector 1 . Then,

$$
\left\{\begin{array}{l}
L_{0}=1-m \\
L_{1}=1+m .
\end{array}\right.
$$

Let $p_{j}$ denote the probability of finding a job in sector $j$. Using the queue lengths in equations (12) and (13), it can be seen that, for each $j$,

$$
\left(p_{j}^{\phi+\frac{1}{a}}+D b p_{j}^{\phi}\right) L_{j}^{\phi}=D z_{j}
$$

where $a=\frac{\theta}{1-\theta}>0$ and $D=\left(\frac{A^{1+a} \theta^{a}}{k^{a}}\right)^{\frac{1}{a}}>0$. Equations (20) and (21) determine the relationship between net mobility and unemployment and thus will be the main focus of this section.

\subsection{Only immobile workers}

Before we analyze the impact of mobility, let us consider the extreme case in which all workers are immobile. Let $p_{\min }$ and $p_{\max }$ denote the job-finding probability in sectors 0 and 1 , respectively, when $L_{j}=1$ for each $j$. Equation (21) shows that when $z_{0}<z_{1}$, the jobfinding probability and employment are higher in sector $1: p_{\min }<p_{\max }$. It is useful to keep this in mind for the analysis below. 


\subsection{Only mobile workers}

Consider the case where all workers are mobile. As some workers leave sector 0, per-worker output will increase in that sector while raising the job-finding rate, $p_{0}$. Specifically, using equation (21), it can be shown that for each $j$,

$$
\frac{d p_{j}}{d L_{j}}=-\frac{p_{j}}{L_{j}}\left(1+\frac{p_{j}^{\phi+\frac{1}{a}} L_{j}^{\phi}}{a \phi D z_{j}}\right)^{-1} .
$$

This equation shows that $\frac{d p_{j}}{d L_{j}}<0$, implying that a decrease in a sector's labor force raises the job-finding rate in that sector. For the same reason, per-worker output of sector 1 will decrease as workers migrate there. Migration will continue until per-worker output is the same in both sectors. Therefore, at equilibrium, the following condition must hold:

$$
z_{0} E_{0}^{-\phi}=z_{1} E_{1}^{-\phi}
$$

Since all workers are mobile, it is straightforward to characterize the queue lengths and employment levels using equation (23). Simplifying (12) and (13) yields:

$$
\frac{1}{\left(q_{j}(0)\right)^{1-\theta}}=\frac{A \theta}{k}\left(z_{j} E_{j}^{-\phi}-b\right)
$$

where $q_{j}(0)>0$ and $0<\theta<1$. This implies that when (23) holds, $q_{0}(0)=q_{1}(0)$. Therefore, at equilibrium, the job-finding rate is the same across sectors. Let $p_{F}$ denote the job-finding probability when there is full arbitrage. Using equations (21) and (22), it can be seen that

$$
p_{\min }<p_{F}<p_{\max }
$$

The employment levels of sectors 0 and 1 are $E_{0}=\left(1-m_{F}\right) p_{F}$ and $E_{1}=\left(1+m_{F}\right) p_{F}$, where $m_{F}$ is the level of net mobility needed to achieve full arbitrage. Equation (23) implies that $m_{F}$ is given by the following equation:

$$
m_{F}=\frac{1-\left(\frac{z_{0}}{z_{1}}\right)^{\frac{1}{\phi}}}{1+\left(\frac{z_{0}}{z_{1}}\right)^{\frac{1}{\phi}}} .
$$

This net flow levels the playing field by allowing the higher productivity of sector 1 to be 
shared between the sectors. ${ }^{6}$

\subsection{Mobile and immobile workers}

We now analyze the case in which there are both mobile and immobile workers. The above results suggest that the relevant range for the fraction of mobile workers is $\left[0, m_{F}\right]$. In this range, net mobility is given by $m=\min \left\{\mu, m_{F}\right\}$. As stated before, this mobility puts upward pressure on the unemployment rate in sector 1 while reducing the unemployment rate of those who are in sector 0 .

\subsubsection{Aggregate employment}

Whether the share of mobile versus immobile workers raises or lowers economy-wide employment is not obvious. We address this issue in the following statement.

Proposition 1. In the net mobility model, an increase in the fraction of mobile workers raises (lowers) economy-wide employment (unemployment).

Proof. Since $E_{j}=p_{j} L_{j}$, equation (21) can be rewritten as

$$
E_{j}^{\phi+\frac{1}{a}}=D L_{j}^{\frac{1}{a}}\left(z_{j}-b E_{j}^{\phi}\right)
$$

for each $j$. Then, using the implicit function theorem, it can be seen that when $1-m_{F}<$ $L_{0}<1$ and $1<L_{1}<1+m_{F}$,

$$
\frac{d E_{j}}{d L_{j}}=\left(\frac{a \phi+1}{p_{j}}+\frac{b \phi D}{p_{j}^{1 / a}}\right)^{-1}
$$

The right-hand side of equation (28) is positive. Therefore, the number of employed workers in a sector is positively related to its labor force: $\frac{d E_{j}}{d L_{j}}>0$. Since $L_{0}=1-m$ and $L_{1}=1+m$, equation (28) implies that the impact of the fraction of mobile workers in the absence of full arbitrage is given by

$$
\frac{d\left(E_{0}+E_{1}\right)}{d \mu}=\left(\frac{a \phi+1}{p_{1}}+\frac{b \phi D}{p_{1}^{1 / a}}\right)^{-1}-\left(\frac{a \phi+1}{p_{0}}+\frac{b \phi D}{p_{0}^{1 / a}}\right)^{-1}
$$

for all $\mu \in\left\{0, m_{F}\right\}$. On the other hand, equation (21) implies that $p_{0}<p_{F}<p_{1}$. and thus the right-hand side of equation (29) is positive. So, the fraction of mobile workers, $\mu$, raises

\footnotetext{
${ }^{6}$ In fact, using state-level data, Blanchard and Katz (1992) show that net mobility reduces the impact of an adverse labor demand shock on local unemployment.
} 
economy-wide employment, $E_{0}+E_{1}$, and, therefore, lowers aggregate unemployment.

Now we analyze how the share of mobile workers affects the unemployment rate among mobile and immobile workers.

\subsubsection{Unemployment of mobile and immobile workers}

Let $u_{0}(\mu)$ and $u_{\infty}(\mu)$ denote the unemployment rate of mobile and immobile workers when the fraction of mobile workers is $\mu$. First we consider the unemployment rate of mobile workers. For this purpose, we point out that when $0 \leq \mu \leq m_{F}$, all mobile workers will be in sector 1 . Since the unemployment rate of sector 1 increases with $\mu$, one can make the following claim:

Corollary 1. In the net mobility model, the share of mobile workers raises their unemployment rate: $\frac{d u_{0}(\mu)}{d \mu}>0$ when $0 \leq \mu<m_{F}$.

The unemployment rate of immobile workers is given by $1-\left(p_{0}+p_{1}\right) / 2$ and the probabilities $p_{0}$ and $p_{1}$ move in the opposite direction as the fraction of mobile workers changes. Therefore, analyzing the impact of net mobility on the unemployment rate of immobile workers amounts to comparing the opposite effects of $p_{0}$ and $p_{1}$.

Corollary 2. Under full arbitrage, labor mobility lowers the unemployment rate among immobile workers - that is to say $u_{\infty}(0)>u_{\infty}\left(m_{F}\right)$.

Proof. When $\mu=0$, the labor force of each sector is 1 and therefore, the average job-finding rate of immobile workers is equal to that of an average worker in the economy. Now let $\mu=m_{F}$. Since there is full arbitrage, all workers in the economy share the same job-finding rate. On the other hand, Proposition 1 shows that the overall job-finding rate increases with mobility. Therefore, the average job-finding rate among immobile workers increases when the fraction of mobile workers increases from zero to $m_{F}$.

Corollary 2 states that the unemployment rate of immobile workers is a globally decreasing function of the fraction of mobile workers. Next we show that a marginal increase in the share of mobile workers can have a non-monotonic impact on the unemployment rate of immobile workers. Specifically, we show that, for plausible parameter values, $u_{\infty}(\mu)$ can be a U-shaped, but globally increasing, function.

Let $\ell_{0}=L_{0} /\left(1-m_{F}\right)$ and $\ell_{1}=L_{1} /\left(1+m_{F}\right)$. Using equation $(21)$, there exists $K>0$ such that

$$
\left(p_{0}^{\phi+\frac{1}{a}}+D b p_{0}^{\phi}\right) \ell_{0}^{\phi}=\left(p_{1}^{\phi+\frac{1}{a}}+D b p_{1}^{\phi}\right) \ell_{1}^{\phi}=K
$$


Then, it can be shown that

$$
\frac{d \ln p_{j}}{d \ln \ell_{j}}=-\frac{1}{1+\frac{K-D b\left(p_{j} \ell_{j}\right)^{\phi}}{a \phi K}} .
$$

Equations (30) and (31) show that when $\ell_{0}=\ell_{1}, \frac{d p_{0}}{d \ell_{0}}=\frac{d p_{1}}{d \ell_{1}}$. Therefore, at the point $\mu=m_{F}$,

$$
\frac{d p_{0}}{d L_{0}}=\frac{1+m_{F}}{1-m_{F}} \frac{d p_{1}}{d L_{1}}>\frac{d p_{1}}{d L_{1}} .
$$

Consequently, there exists a non-negative number $\tilde{m}$ such that, for $\tilde{m}<\mu<m_{F}$,

$$
\frac{d\left(p_{0}+p_{1}\right)}{d \mu}>0
$$

and

$$
\frac{d u_{\infty}(\mu)}{d \mu}<0
$$

Thus, when the economy is at full arbitrage, a marginal decrease in the fraction of mobile workers lowers the job-finding rate of immobile workers. Equivalently, as the fraction of mobile workers approaches the level of mobility needed to achieve full arbitrage, an increase in the fraction of mobile workers lowers the unemployment rate of immobile workers.

However, inequality (32) may not always hold for all $\mu \in\left\{0, m_{F}\right\}$, meaning that a marginal increase in the share of mobile workers may raise the unemployment rate of immobile workers. Specifically, using equation (31), it can be seen that when the fraction of mobile workers is much lower than $m_{F}$ or, equivalently, when the gap between $\ell_{0}$ and $\ell_{1}$ is large, the inequality may not hold. To see the point, consider the case where the gap between $\ell_{0}$ and $\ell_{1}$ is largest, which is when the fraction of mobile workers, $\mu$, is initially zero and thus $L_{j}=1$ for each $j$. Let $R_{j}$ denote the absolute value of $\frac{d p_{j}}{d L_{j}}$ when $L_{j}=1$ :

$$
R_{j}=-\left.\frac{d p_{j}}{d L_{j}}\right|_{L_{j}=1}=p_{j}\left(1+\frac{p_{j}^{\phi+\frac{1}{a}}}{a \phi D z_{j}}\right)^{-1} .
$$

Then, it follows that

$$
\frac{d \ln R_{j}}{d z_{j}}=\frac{a}{z_{j}(\gamma+a \phi)}\left(1-\frac{1}{a} \frac{\gamma(1-\gamma)}{\gamma+a \phi}\right),
$$

where $\gamma=p_{j}^{\phi+1 / a} /\left(D z_{j}\right)$. It can be seen that $1-\gamma$ is the replacement ratio and thus $0<\gamma \leq 1$. Moreover, we have $0<\phi<1, a=\theta /(1-\theta)>0$ and $z_{j}>0$ for each $j$. Therefore, the right-hand side of equation (34) can be positive. This means that when the fraction of mobile workers is very low, mobility can have a greater impact on the job-finding rate of a sector 
with a higher technology shock. Therefore, a marginal increase in the fraction of mobile workers can raise the unemployment rate of immobile workers. It should, however, be noted that $\frac{d \ln R_{j}}{d z_{j}}$ is not always positive. For example, when the elasticity of the matching function, $\theta$, is sufficiently low (thus $a$ is small), the right-hand side of equation (34) is negative. Under such circumstances, the unemployment rate of immobile workers will be a strictly decreasing function of the share of mobile workers. For the remainder of the section, we illustrate these points numerically.

\subsection{Numerical example}

We start with a benchmark model with the following features: a) no immobile workers, $\mu=1$; b) symmetric sector shocks, $z_{0}=z_{1}=1$; c) unit queue lengths at $x=0, q_{0}(0)=q_{1}(0)=1$; and d) a job-finding rate of 0.45 at $x=0$ for each $j$. The parameter values associated with this calibration are presented in Table 1 . Consider the case where $z_{0}=1$ and $z_{1}=1.8$. Using equation (26), the share of mobile workers needed to achieve full arbitrage is $m_{F}=0.626$ $(62.6 \%)$. Thus, the relevant range for the share of mobile workers is $[0,0.626]$.

Figure 1 displays aggregate unemployment and the unemployment rates of mobile and immobile workers as a function of the share of mobile workers. It shows that a higher share of mobile workers is associated with lower aggregate unemployment. The figure also illustrates that weaker arbitrage has a positive effect on the workers who find themselves in the more productive sector. Thus, sector 1 workers and mobile workers have lower unemployment rates as $\mu$ decreases. Consistent with the analytical results, the share of mobile workers has a non-monotonic impact on the unemployment rate of immobile workers. Figure 2 shows that when the elasticity of the matching function, $\theta$, is sufficiently low, the unemployment rate of immobile workers is a strictly decreasing function of the share of mobile workers. Finally, both Figures 1 and 2 show that the unemployment rate of immobile workers is a globally decreasing function of the share of mobile workers: $u_{\infty}(0)>u_{\infty}(0.626)$ for both cases.

\section{Gross mobility effects}

Here the technology shock of each sector is normalized to 1 (i.e., $z_{0}=z_{1}=1$ ), while workers can differ by their idiosyncratic productivity shock (i.e., $\sigma>0$ ). Our analysis in this section focuses mainly on sector 1 . Since the two sectors are symmetric with respect to $x$, the results for sector 0 can be obtained analogously. 


\subsection{Sectoral employment}

Since mobility is driven by the idiosyncratic shock, for each mobile worker in sector 0 willing to relocate, there will be another mobile worker in sector 1 also willing to relocate. Thus, in this version of the model, labor mobility has no impact on the size of the labor force of each sector. However, it affects the overall productivity of workers within each sector. Specifically, since, on average, in-migrants are more productive than incumbent workers, an increase in the share of mobile workers will raise the relative share of more productive workers within each sector. This shift in the within-sector wage distribution, in turn, affects employment.

Proposition 2. In the gross mobility model, the share of mobile (immobile) workers raises (lowers) employment in both sectors.

Proof. The job-finding rate of sector 1 can be rewritten as

$$
p_{1}(x)=D^{a}\left(\frac{1+x}{E_{1}^{\phi}}-b\right)^{a}
$$

where, as before, $D>0$ and $a>0$. Let $H_{j}(x \mid \mu)$ denote the productivity distribution of workers of sector $j$ over the shock $x$ after workers relocate when the share of mobile workers is $\mu$. Then, employment in sector 1 can be given by

$$
E_{1}=D^{a} \int\left(\frac{1+x}{E_{1}^{\phi}}-b\right)^{a} d H_{1}(x \mid \mu) .
$$

Consider the following function:

$$
\Gamma\left(E_{1}, \mu\right)=E_{1}-D^{a} \int\left(\frac{1+x}{E_{1}^{\phi}}-b\right)^{a} d H_{1}(x \mid \mu) .
$$

Since $\Gamma\left(E_{1}, \mu\right)=0$,

$$
\frac{d E_{1}}{d \mu}=-\frac{\frac{\partial \Gamma\left(E_{1}, \mu\right)}{\partial \mu}}{\frac{\partial \Gamma\left(E_{1}, \mu\right)}{\partial E_{1}}}
$$

Clearly, $\frac{\partial \Gamma\left(E_{1}, \mu\right)}{\partial E_{1}}$ is positive (see equation (37)). On the other hand, when the fraction of mobile workers, $\mu$, increases, overall productivity in the sector increases. Since the probability of finding a job increases with productivity (see equation (35)), the right-hand side of equation (36) increases for a given level of sectoral employment, implying that $\frac{\partial \Gamma\left(E_{1}, \mu\right)}{\partial \mu}$ is negative. Therefore, for all $\mu \in(0,1)$,

$$
\frac{d E_{1}}{d \mu}>0
$$


Consequently, aggregate employment also increases with the share of mobile workers. This increase is due to the increased fluidity of the labor force. When the labor market is increasingly mobile, there is more reallocation of the labor force. Therefore, a lower fraction of workers will be stuck in jobs in which they are far less productive than they would otherwise be in the other sector of the economy. So, as the share of mobile workers increases, the overall sectoral match quality goes up while lowering aggregate unemployment.

\subsection{Unemployment of mobile and immobile workers}

As before, let $u_{0}(\mu)$ and $u_{\infty}(\mu)$ denote the unemployment rate of mobile and immobile workers when the fraction of mobile workers is $\mu$.

Corollary 3. In the gross mobility model, the share of mobile workers raises the unemployment rate of both mobile and immobile workers: $\frac{d u_{0}(\mu)}{d \mu}>0$ and $\frac{d u_{\infty}(\mu)}{d \mu}>0$ for all $\mu \in(0,1)$.

Proof. Since the distribution of immobile workers over the productivity shock $x$ does not change, their job-finding rate is determined by sectoral employment (see equation (35)). Since the share of mobile workers raises sectoral employment (see Proposition 2), it will increase the unemployment rate of immobile workers. The distribution (not the size) of mobile workers over the productivity shock $x$ also remains unaffected when the share of mobile versus immobile workers shifts. Therefore, their job-finding rate also decreases with the fraction of mobile workers.

These results may seem inconsistent with Proposition 2. Specifically, the proposition states that the aggregate unemployment rate goes down with the fraction of mobile workers, while Corollary 3 say that the unemployment rates of the two groups increase as the fraction increases. The reason for this seemingly opposite prediction is that the unemployment rate is higher for immobile workers. To see this, consider the following decomposition:

$$
u(\mu)=\mu u_{0}(\mu)+(1-\mu) u_{\infty}(\mu)
$$

where $u(\mu)$ is the aggregate unemployment rate when the fraction of mobile workers is $\mu$. Differentiating the equation with respect to $\mu$, one can obtain

$$
\underbrace{u^{\prime}(\mu)}_{\text {negative }}=\underbrace{\left[u_{0}(\mu)-u_{\infty}(\mu)\right]}_{\text {negative }}+\underbrace{\left[\mu u_{0}^{\prime}(\mu)+(1-\mu) u_{\infty}^{\prime}(\mu)\right]}_{\text {positive }} .
$$


This equation, along with Proposition 2 and Corollary 3 , shows that the level effect, $u_{0}(\mu)-$ $u_{\infty}(\mu)$, dominates the effect resulting from changes in the unemployment rates of the two groups, $\mu u_{0}^{\prime}(\mu)+(1-\mu) u_{\infty}^{\prime}(\mu)$. So, the share of mobile workers lowers the aggregate unemployment rate while raising the unemployment rates of mobile and immobile workers.

\subsection{Numerical example}

To illustrate these effects numerically, the model is recalibrated. The new calibration targets are similar to those in the net mobility model, but this time it reflects the productivity dispersion. We set the productivity dispersion parameter $\sigma$ to 0.2 , implying that, depending on the share of mobile workers, the variation of productivity is $6-12 \%$. The parameters are summarized in the third column of Table 1.

The probability density function, $h_{1}(x \mid \mu)$, associated with the distribution function $H_{1}(x \mid \mu)$ is

$$
h_{1}(x \mid \mu)= \begin{cases}2.5(1-\mu) & \text { if }-0.2 \leq x<0 \\ 2.5(1+\mu) & \text { if } 0 \leq x \leq 0.2 .\end{cases}
$$

So, overall productivity increases with $\mu$, the share of mobile workers. The queue length is graphed in Figure 3. Consistent with equations (12) and (13), the queue length increases with productivity $y_{j}(x)$. More important, given the shock $x$, the queue length increases as the fraction of mobile workers increases. The unemployment rates of sub-groups are presented in Figure 4. They show that as the fraction of mobile workers increases, the unemployment rate of both mobile and immobile workers increases, while aggregate unemployment decreases, which is consistent with equation (38).

\section{Conclusion}

This paper has developed a simple equilibrium model of sectoral reallocation with heterogeneous moving costs in which there can be simultaneous in- and outflows at the sectoral level. In the model, labor mobility is influenced by a sectoral level shock and an idiosyncratic shock specific to the sector-worker match. According to the model, aggregate unemployment and the share of mobile workers are negatively related. More important, the model reveals that the interaction between mobile and immobile workers can be different depending on how mobility is modeled. When labor mobility is driven by an idiosyncratic sector-worker match effect, the share of mobile workers raises the unemployment rate of immobile workers. However, when labor mobility is driven by a sectoral level aggregate disturbance, mobile workers can have a non-monotonic, but globally negative impact on the unemployment rate 
of immobile workers. These results suggest that focusing only on aggregate and sector-level variables might introduce an important oversight regarding the underlying economic mechanism through which workers interact across sectors. Therefore, the micro-level relationship between mobility and wages might be key to understanding unemployment in a multi-sector economy.

Clearly, the model considered in this paper is too simple to pinpoint conditions under which the gross mobility effect dominates the net mobility effect, or vice-versa. Therefore, an interesting exercise would measure these effects while allowing for a more realistic setting in a particular context, such as the interaction between the labor market and homeownership. Moreover, a multi-period dimension can be added to introduce persistence for both idiosyncratic and sector-wide shocks. This will help quantify the relative magnitude of these two shocks using micro data on labor income. Also, one may need to take into account

life-cycle effects by considering different moving costs for young and old workers. Future research should look at these important directions. Nevertheless, the current study can be viewed as an important step toward understanding how the variability of labor mobility affects unemployment.

\section{References}

Blanchard, Olivier and Lawrence Katz (1992). "Regional Evolutions," Brookings Papers on Economic Activity, 23: 1-61.

Carrillo-Tudela, Carlos and Ludo Visschers (2013). "Unemployment and Endogenous Reallocation over the Business Cycle," IZA Discussion Paper 7124.

Coen-Pirani, Daniele (2010). "Understanding Gross Worker Flows Across U.S. States," Journal of Monetary Economics, 57 (7): 769-784.

Coulson, N. Edward and Lynn M. Fisher (2009). "Housing tenure and labor market impacts: The search goes on," Journal of Urban Economics, 65.

Greenwood, Michael J. (1997). "Internal Migration in Developed Countries," in Mark R. Rosenzweig and Oded Stark, eds., "Handbook of Population and Family Economics Vol. 1B," New York: North Holland.

Head, Allen and Huw Lloyd-Ellis (2012). "Housing Liquidity, Mobility, and the Labour Market," Review of Economic Studies, 79.

Jovanovic, Boyan and Robert Moffitt (1990). "An Estimate of a Sectoral Model of Labor Mobility," Journal of Political Economy, 98 (4): 827-852.

Kambourov, Gueorgui and Iourii Manovskii (2009). "Occupational Mobility and Wage Inequality," Review of Economic Studies, 76: 731-759. 
Lkhagvasuren, Damba (2007). Local Labor Market Dynamics with Net and Gross Mobility: Implications on Unemployment and Wages, Ph.D. thesis, University of Rochester.

Lkhagvasuren, Damba (2012). "Big Locational Unemployment Differences Despite High Labor Mobility," Journal of Monetary Economics, 59 (8): 798-814.

Lucas, Robert E., Jr. and Edward C. Prescott (1974). "Equilibrium Search and Unemployment," Journal of Economic Theory, 7: 188-209.

Moen, Espen R. (1997). "Competitive Search Equilibrium," Journal of Political Economy, 105 (2): $385-411$.

Mortensen, Dale T. and Éva Nagypál (2007). "More on Unemployment and Vacancy Fluctuations," Review of Economic Dynamics, 10 (3): 327-347.

Moscarini, Giuseppe and Kaj Thomsson (2007). "Occupational and Job Mobility in the US." Scandinavian Journal of Economics, 109: 807-836.

Moscarini, Giuseppe and Francis Vella (2008). "Occupational Mobility and the Business Cycle," Working Paper 13819, NBER.

Munch, Jakob Roland, Michael Rosholm and Michael Svarer (2006). "Are Homeowners Really More Unemployed?" The Economic Journal, 116 (514): 991-1013.

Oswald, Andrew (1997). "Thoughts on NAIRU (correspondence)," Journal of Economic Perspectives, 11 (1): 227-228.

Oswald, Andrew (1999). "The Housing Market and Europe's Unemployment: A NonTechnical Paper," Mimeo, Warwick University.

Petrongolo, Barbara and Christopher A. Pissarides (2001). "Looking into the Black Box: A Survey of the Matching Function," Journal of Economic Literature, 39 (2): 390-431.

Rogerson, Richard (1987). "An Equilibrium Model of Sectoral Reallocation," Journal of Political Economy, 95 (4): 824-834.

Rogerson, Richard, Robert Shimer and Randall Wright (2005). "Search Theoretic Models of the Labor Market: A Survey," Journal of Economic Literature, 43 (4): 959-988.

Rogerson, Richard, Lodewijk P. Visschers and Randall Wright (2009). "Labor Market Fluctuations in the Small and in the Large," International Journal of Economic Theory, 5 (1): 125-137.

Topel, Robert H. (1986). "Local Labor Markets," Journal of Political Economy, 94 (3): S111-S143.

Valletta, Robert G. (2012). "House Lock and Structural Unemployment," IZA Discussion Paper 7002. 
Table 1: Parameter Values for Numerical Examples

\begin{tabular}{cccl}
\hline parameter & $\begin{array}{c}\text { net } \\
\text { mobility } \\
\text { model }\end{array}$ & $\begin{array}{c}\text { gross } \\
\text { mobility } \\
\text { model }\end{array}$ & description \\
\hline$A$ & 0.450 & same & efficiency of the matching technology \\
$\theta$ & 0.500 & same & elasticity of the matching technology \\
$\phi$ & 0.400 & same & elasticity of labor productivity to sectoral employment \\
$b$ & 0.630 & same & unemployment benefits \\
$k$ & 0.168 & 0.146 & vacancy posting cost \\
$\sigma$ & 0 & 0.200 & dispersion of idiosyncratic productivity \\
\hline
\end{tabular}

Notes: The value $\theta=0.5$ is consistent with Petrongolo and Pissarides (2001). The parameter $k$ is chosen to normalize the queue lengths $q_{0}(0)$ and $q_{1}(0)$ to unity. Given this normalization, the value of $A$ measures the job-finding rate, which is set to 0.45 . The value $b=0.63$ implies that in the benchmark model, the replacement ratio is 0.46 , which is in the range of estimates found in Mortensen and Nagypál (2007). The value of $\phi$ implies that the elasticity of aggregate output to employment is $0.6(=1-0.4)$. 
Figure 1: Unemployment in Net Mobility Model: Benchmark, $\theta=0.5$
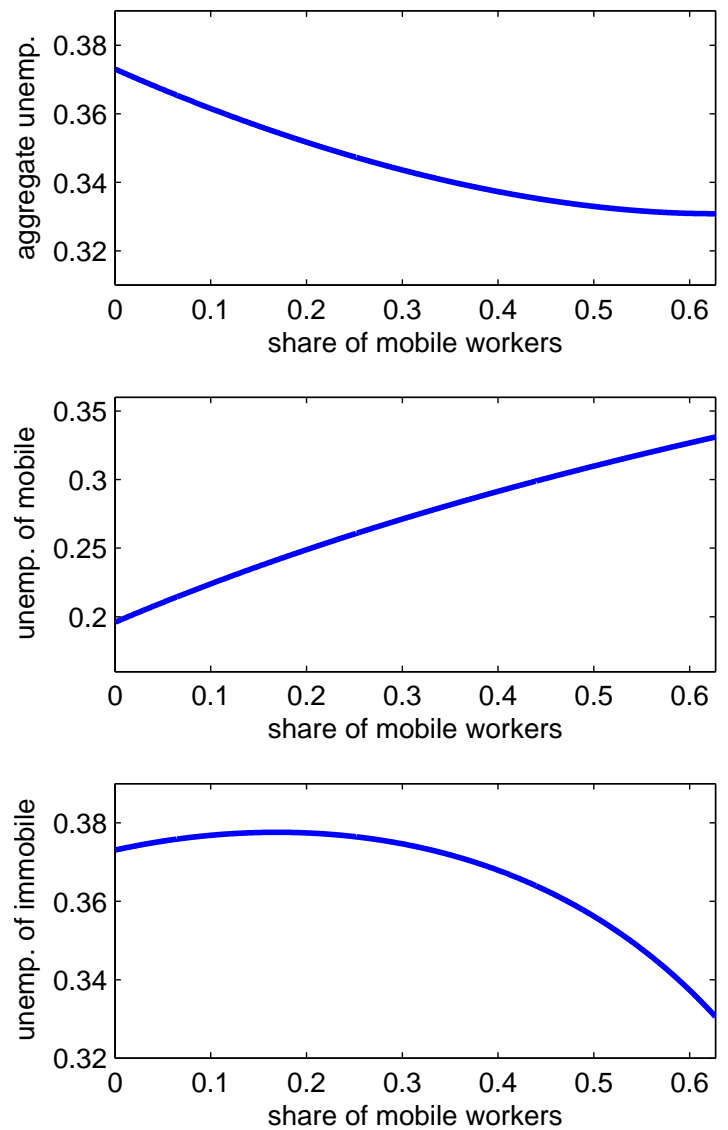

Notes: This figure shows how unemployment responds to the share of mobile workers, $\mu$, in the net mobility model when $\theta=0.5$ and $z_{1}=1.8$, while the other parameters are at their benchmark values. The upper panel shows aggregate unemployment $u$. The middle panel shows the unemployment rate of mobile workers, $u_{0}(\mu)$, while the lower panel shows the unemployment rate of immobile workers $u_{\infty}(\mu)$. See Table 1 for the parameter values used for the diagram. 
Figure 2: Unemployment in Net Mobility Model: $\theta=0.1$
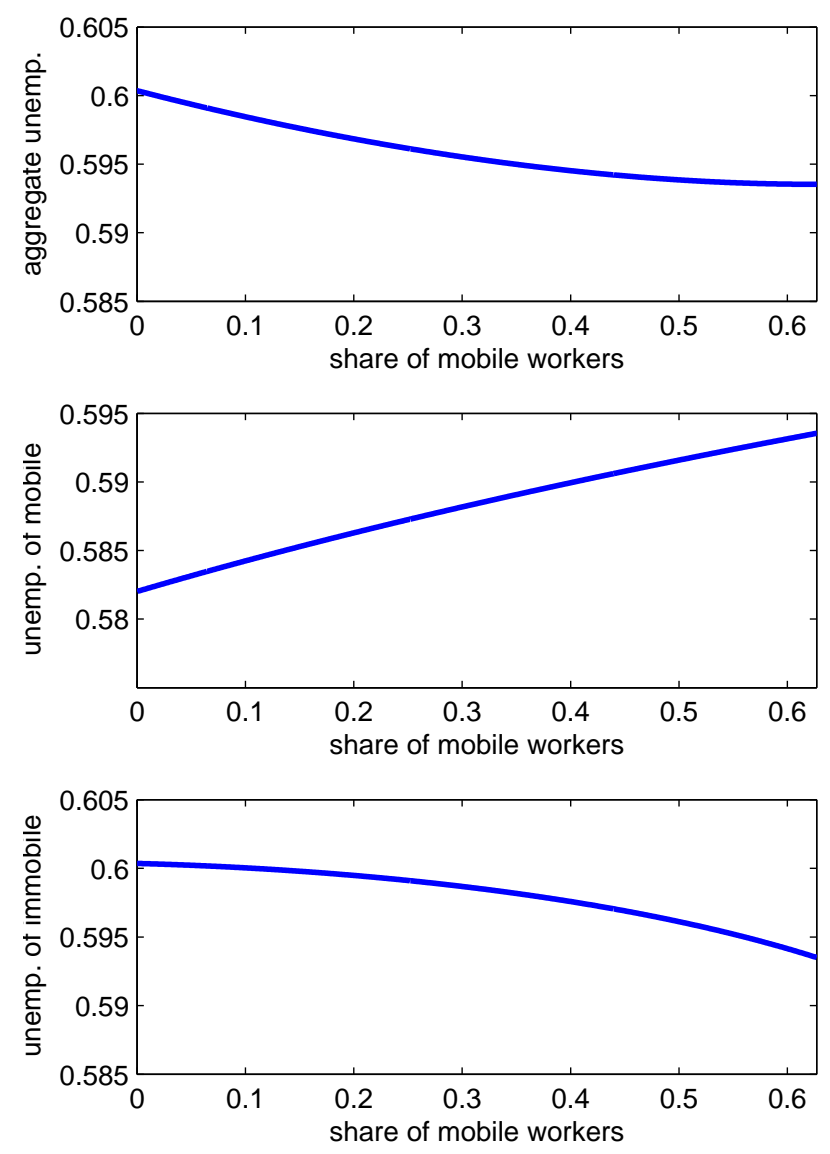

Notes: This figure shows how unemployment responds to the share of mobile workers, $\mu$, in the net mobility model when $\theta=0.1$ and $z_{1}=1.8$, while the other parameters are at their benchmark values. The lower panel shows that when the elasticity of the matching function, $\theta$, is sufficiently low, the unemployment rate of immobile workers is a strictly decreasing function of the share of mobile workers. 
Figure 3: Queue Length in Gross Mobility Model

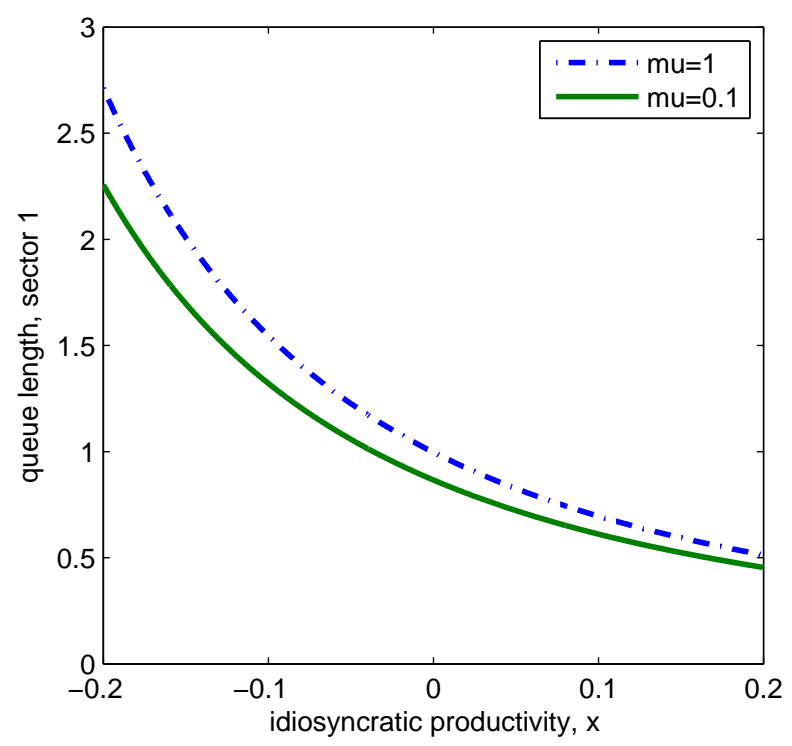

Notes: This figure shows that the queue length in sector 1 decreases with productivity and that the share of mobile workers, $\mu$, raises the queue length at each productivity level. (The queue length in sector 0 is a mirror reflection of the curves across the vertical line $x=0$.) See Section 4.3 for numerical details. 
Figure 4: Unemployment in Gross Mobility Model
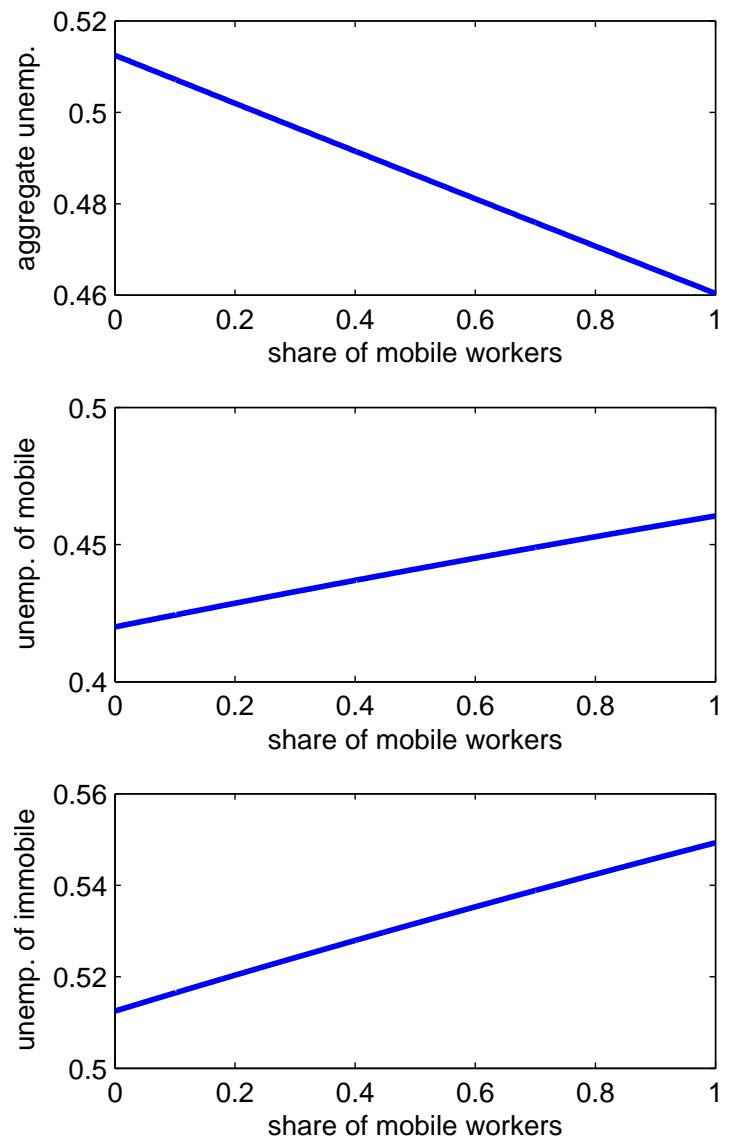

Notes: This figure illustrates the impact of the share of mobile workers on unemployment in the gross mobility model considered in Section 4. The upper panel shows aggregate unemployment, while the middle and lower panels display the unemployment rate of mobile and immobile workers, respectively. See Section 4.3 for numerical details. 